Revista Brasil. Bot., V.28, n.4, p.713-726, out.-dez. 2005

\title{
Anatomia foliar como subsídio para a taxonomia de espécies de Forsteronia G. Mey. (Apocynaceae) dos cerrados paulistas ${ }^{1}$
}

\author{
MARIA CAROLINA S. RIO², LUIZA S. KINOSHITA² e MARÍLIA M. CASTRO ${ }^{2,3}$
}

(recebido: 13 de janeiro de 2005; aceito: 13 de outubro de 2005)

\begin{abstract}
Leaf anatomy as subsidy to the taxonomy of Forsteronia G.Mey. species (Apocynaceae) in cerrados of São Paulo). The foliar anatomy of four cerrado species of Forsteronia was investigated in order to determine characters that could help to identify individuals collected in vegetative stage. Specimens of F. pubescens A.DC., F. thyrsoidea (Vell.) Müll.Arg., F. australis Müll.Arg., and F. glabrescens Müll.Arg. were collected in Moji-Guaçu and Itirapina cities (São Paulo state, Brazil). Results support the use of foliar features to achieve determination of individuals in vegetative state. Forsteronia australis differs from F. glabrescens in two macromorphological and four anatomical characters: 1. petiole outline in transverse sections; 2. occurrence of phloem strand above the petiole's midvein; 3 . occurrence of secretory hypoderm in the petiole; 4 . occurrence of trichomes in the domatia; 5. occurrence of secretory idioblasts and the aspect of their secretion; 6. axilar colleter type. F. pubescens is distinguished from $F$. thyrsoidea by eight characters: 1 . petiole outline in transverse sections; 2 . occurrence of phloem strands above the petiole midrib; 3. midvein shape; 4. position of secretory idioblasts in the petiole; 5. mesophyll type; 6. occurrence of crystal idioblasts; 7. occurrence of secretory idioblasts around main vascular bundle; 8 . occurrence of axilar branched colleters. This is the first work describing domatia anatomy and sessile and branched colleters in vegetative organs of species of Apocynaceae. The characters described herein have taxonomic significance and are useful to identify Forsteronia species, thus contributing to a better delimitation of similar species found in cerrado vegetation of São Paulo.
\end{abstract}

Key words - "cerrado" vegetation, domatia, Forsteronia, leaf anatomy, secretory structures

RESUMO - (Anatomia foliar como subsídio para a taxonomia de espécies de Forsteronia G.Mey (Apocynaceae) dos cerrados paulistas). Quatro espécies de Forsteronia encontradas em regiões de cerrado tiveram sua anatomia foliar investigada com o objetivo de levantar caracteres que auxiliem a identificar indivíduos em estádio vegetativo. Indivíduos de F. australis Müll.Arg., F. glabrescens Müll.Arg., F. pubescens A.DC. e F. thyrsoidea (Vell.) Müll.Arg. foram coletados em Moji-Guaçu e Itirapina (São Paulo, Brasil). De acordo com os dados obtidos, é possível identificar indivíduos em estádio vegetativo através da estrutura foliar. Dois caracteres macromorfológicos e quatro anatômicos diferenciam F. australis de F. glabrescens: 1. contorno do pecíolo em secção transversal; 2. ocorrência de cordão de floema acima do feixe vascular no pecíolo; 3. ocorrência de hipoderme secretora no pecíolo; 4. ocorrência de indumento nas domácias; 5. ocorrência de idioblastos secretores e aspecto da sua secreção; 6. tipo dos coléteres axilares. F. pubescens distingue-se de F. thyrsoidea por oito caracteres: 1. contorno do pecíolo em secção transversal; 2. ocorrência de cordões de floema acima do feixe vascular no pecíolo; 3 . formato do feixe vascular; 4. posição dos idioblastos secretores no pecíolo; 5. tipo de mesofilo; 6. ocorrência de idioblastos cristalíferos; 7. ocorrência de idioblastos secretores ao redor do feixe vascular mediano; 8. ocorrência de coléter axilar ramificado. A anatomia das domácias e os coléteres dos tipos séssil e ramificado são ineditamente descritos para órgãos vegetativos de espécies de Apocynaceae. Os caracteres levantados têm importância taxonômica e são úteis na identificação das espécies de Forsteronia, contribuindo dessa forma para uma melhor delimitação das espécies consideradas semelhantes ocorrentes nos cerrados paulistas.

Palavras-chave - anatomia foliar, cerrado, domácias, estruturas secretoras, Forsteronia

\section{Introdução}

Incluído na subfamília Apocynoideae Burnett (Endress \& Bruyns 2000), Forsteronia G.Mey. é

\footnotetext{
1. Parte da tese de doutorado de Maria Carolina S. Rio, Programa de Pós-graduação em Biologia Vegetal, Instituto de Biologia, Universidade Estadual de Campinas.

2. Universidade Estadual de Campinas, Instituto de Biologia, Departamento de Botânica, Caixa Postal 6109, 13083-970 Campinas, SP, Brasil.

3._Autor para correspondência: mariliac@ unicamp.br
}

constituído por 46 espécies de distribuição neotropical, cujos representantes são predominantemente lianas, raro arbustos; para o Brasil, já foram registradas 24 espécies (Hansen 1985). O levantamento da Flora Fanerogâmica do Estado de São Paulo (Koch \& Kinoshita 2005) localizou nove espécies, das quais quatro, F. australis Müll.Arg., F. glabrescens Müll.Arg., F. pubescens A.DC. e F. thyrsoidea (Vell.) Müll.Arg., podem ser encontradas em regiões de cerrado. Em estádio vegetativo, $F$. australis é muito semelhante a $F$. glabrescens, e F. thyrsoidea pode ser facilmente confundida com 
F. pubescens, sendo diferenciadas apenas por caracteres essencialmente reprodutivos.

Poucos trabalhos referentes aos caracteres anatômicos vegetativos de espécies de Apocynaceae foram realizados, destacando-se aqueles relacionados à arquitetura foliar de 29 espécies pertencentes a 19 gêneros (Mohan \& Inamdar 1982), anatomia de folhas xeromórficas em espécies de Allamanda, Thevetia e Vinca (Fjell 1983), anatomia do sistema aéreo, coléteres e ultra-estrutura dos laticíferos em espécies de Mandevilla (Appezzato-da-Glória \& Estelita-Teixeira 1992, Appezzato-da-Glória \& Estelita 1997, 2000).

Domácias estão presentes em 37 espécies de Apocynaceae, estando incluída $F$. brasiliensis A.DC. (Brouwer \& Clifford 1990, Gregory 1990). Tais estruturas são mencionadas para algumas espécies de Forsteronia na obra de revisão de Hansen (1985) e foram adotadas como um caráter importante para separar grupos em chave de identificação de espécies (Koch \& Kinoshita 2005). Glândulas nodais e foliares, posicionadas na base da nervura mediana, foram registradas para o gênero (Hansen 1985) e identificadas como coléteres em estudos recentes de representantes dessa família (Rio et al. 2002, Koch \& Kinoshita 2005).

Solereder (1908) descreveu a ocorrência de laticíferos e de floema intraxilemático para as folhas de Forsteronia. Metcalfe \& Chalk $(1950,1979)$ citaram o gênero no item de anatomia geral, mas não o mencionaram nas descrições detalhadas. Faltam dados anatômicos sobre as espécies brasileiras de Forsteronia, uma vez que estudos desta natureza ainda não foram realizados (Hansen 1985).

A presente investigação teve por objetivo levantar caracteres anatômicos foliares que pudessem auxiliar na taxonomia do gênero, principalmente em espécies de cerrado, facilitando a distinção entre espécies semelhantes ou próximas, que são difíceis de serem diferenciadas pela morfologia externa. Especial atenção foi dada à caracterização anatômica das domácias e das estruturas secretoras foliares.

\section{Material e métodos}

Ramos vegetativos de indivíduos de Forsteronia australis Müll.Arg., F. glabrescens Müll.Arg., F. pubescens A.DC. e F. thyrsoidea (Vell.) Müll.Arg. foram coletados na Reserva Biológica e Estação Experimental de Moji-Guaçu (Fazenda Campininha) e/ou na Estação Ecológica e Experimental de Itirapina, dependendo da disponibilidade de material; material testemunha para cada indivíduo foi providenciado e está sendo incorporado no Herbário UEC. Dois indivíduos de cada espécie (três no caso de F. pubescens) foram utilizados nos estudos morfológicos; para $F$. thyrsoidea e $F$. pubescens, recorreu-se também a material herborizado (tabela 1). A identificação dos indivíduos foi realizada pela Profa. Dra. Luiza Sumiko Kinoshita e pelo Dr. André Olmos Simões. Observações sobre a fenologia dos indivíduos marcados da Fazenda Campininha foram realizadas mensalmente durante o ano de 2003.

O material coletado foi fixado em FAA (Johansen 1940) por 24 horas. Alguns indivíduos foram fixados em formalina neutra tamponada (FNT) por 48 horas (Lillie 1948 apud Clark 1973) e em sulfato ferroso em formalina (SFF) por 48 horas (Johansen 1940). Todo o material fixado foi estocado em etanol 70\%. Folhas adultas foram selecionadas do material fixado ou herborizado e ápices caulinares vegetativos foram isolados do material fixado. A região mediana da folha adulta e a região proximal do pecíolo (junto à base da lâmina foliar) foram utilizadas para o estudo estrutural; a nervura mediana e a margem da lâmina foram isoladas em peças com cerca de $1 \mathrm{~cm}^{2}$.

Ápices vegetativos e peças isoladas das folhas adultas foram transferidos para álcool butílico 70, desidratados pela série butílica (Johansen 1940) e incluídos em Paraplast. Cortes

Tabela 1. Relação dos espécimes de Forsteronia.

Table 1. List of Forsteronia specimens.

\begin{tabular}{|c|c|c|c|c|}
\hline Espécie & Indivíduo & Local (tipo de vegetação) & Coletor e número & Data \\
\hline \multirow[t]{2}{*}{ Forsteronia australis } & AUS1 & Moji-Guaçu (cerrado) & M.C.S. do Rio et al. 21 & 6.I.2002 \\
\hline & AUS2 & Moji-Guaçu (cerrado) & M.C.S. do Rio et al. 26 & 6.II.2003 \\
\hline \multirow[t]{2}{*}{ F. glabrescens } & GLA1 & Moji-Guaçu (cerrado) & M.C.S. do Rio et al. 19 & 22.XI.2001 \\
\hline & GLA8 & Itirapina (cerrado) & M.C.S. do Rio et al. 32 & 8.XI.2003 \\
\hline \multirow[t]{3}{*}{ F. pubescens } & PUB1 & Itirapina (cerrado) & M.C.S. do Rio et al. 28 & 8.XI.2003 \\
\hline & PUB94 & São José do Rio Pardo (cerradão) & L.S. Kinoshita \& A. Sartori 94-19 & 8.XI.1994 \\
\hline & PUB95 & Suzanópolis (cerrado) & M.R. Pereira-Noronha et al. 1583 & VIII.1995 \\
\hline \multirow[t]{2}{*}{ F. thyrsoidea } & THY1 & Itirapina (cerrado) & M.C.S. do Rio et al. 29 & 8.XI.2003 \\
\hline & THY98 & Pilar do Sul - Sarapuí (cerrado) & A.M.G.A. Tozzi et al. 357 & 3.XII.1998 \\
\hline
\end{tabular}


seriados longitudinais e transversais, com espessura de 12 a $16 \mu \mathrm{m}$, foram obtidos em micrótomo rotativo, corados com safranina e azul de astra (Gerlach 1969) e as lâminas montadas em resina sintética Permount. Os cortes obtidos a partir do material fixado em SFF (Johansen 1940), específico para evidenciar compostos fenólicos, foram desparafinizados, diafanizados e montados em resina sintética.

Folhas adultas selecionadas de exsicatas de F. pubescens e F. thyrsoidea depositadas no Herbário UEC foram hidratadas; o material permaneceu em hidróxido de potássio para distensão dos tecidos (Smith \& Smith 1942) e folhas inteiras foram utilizadas para a clarificação da lâmina foliar. A região mediana da lâmina foliar e a região proximal do pecíolo foram isoladas para inclusão das peças em resina plástica. As peças isoladas foram desidratadas rapidamente, transferidas para etanol $100 \%$ e incluídas em resina plástica (Gerrits 1991). Cortes com $10 \mu \mathrm{m}$ de espessura foram obtidos em micrótomo rotativo e corados com azul de toluidina 0,05\% pH 4,7 (O'Brien et al. 1964); as lâminas permanentes, montadas em resina sintética.

Para a clarificação das lâminas foliares, foram utilizadas folhas adultas fixadas em FAA ( $F$. australis e $F$. glabrescens) ou hidratadas de material herborizado ( $F$. pubescens e $F$. thyrsoidea). As folhas foram diafanizadas e coradas
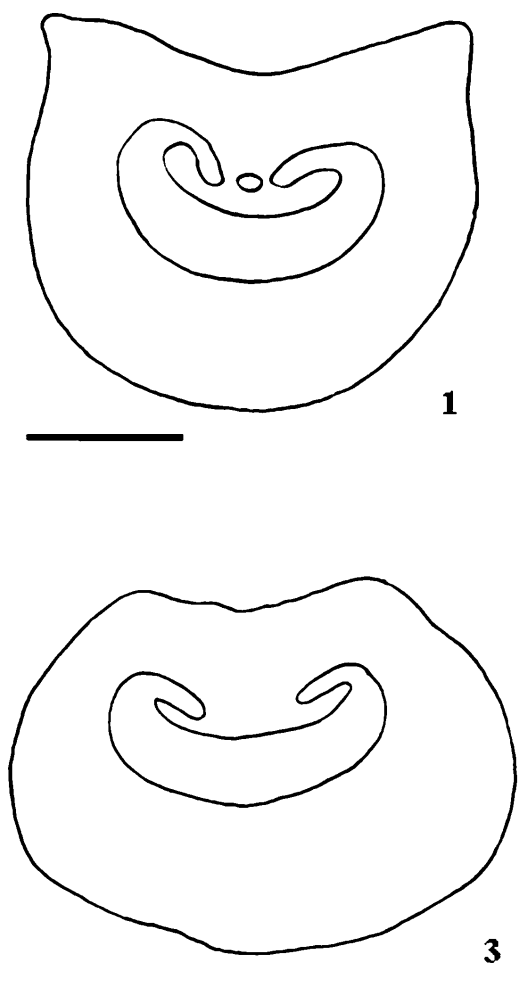

segundo Shobe \& Lersten, modificado por Monteiro et al. (1979), para estudo da epiderme em vista frontal, com especial atenção às domácias.

Os esquemas dos pecíolos foram obtidos em câmara clara acoplada a microscópio. As ilustrações foram efetuadas através de fotomicrografias coloridas obtidas em microscópio Olympus BX51 com o uso de filme Kodak ProImage 100 ou Kodak Gold 100; as escalas foram obtidas através da projeção de lâmina micrométrica nas mesmas condições ópticas utilizadas para as ilustrações. Todas as figuras foram digitalizadas com alta resolução (600 dpi) e as pranchas montadas em meio digital.

\section{Resultados}

Os dados referentes ao pecíolo (figuras 1-17) e lâmina foliar (figuras 18-41) permitem diferenciar Forsteronia australis Müll.Arg. (figuras 1, 5-8, 18-23) de F. glabrescens Müll.Arg. (figuras 2, 9-12, 24-29) e F. pubescens A.DC. (figuras 3, 13, 14, 30-36) de F. thyrsoidea (Vell.) Müll.Arg. (figuras 4, 15-17, 37-41). Pecíolo - O contorno da secção transversal do pecíolo (figuras 1-4) é um caráter macromorfológico útil na
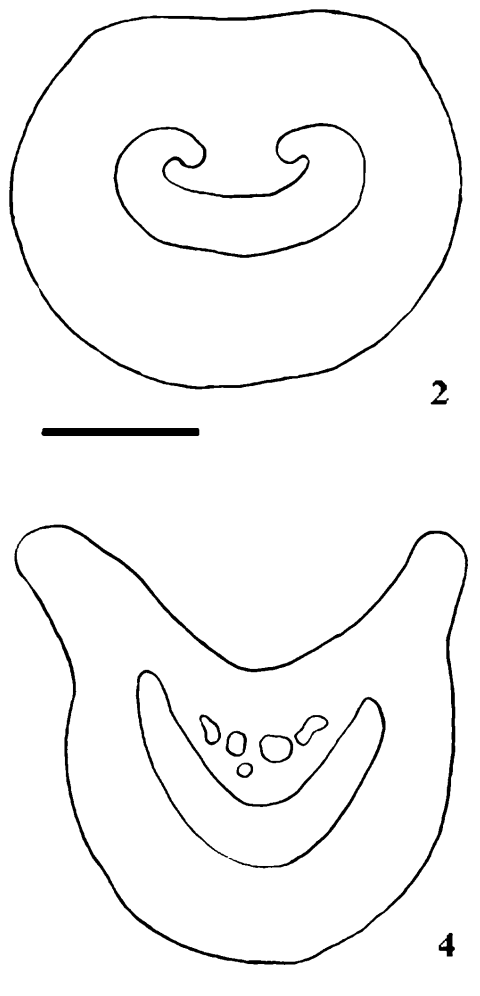

Figuras 1-4. Esquemas das secções transversais da região proximal dos pecíolos obtidos dos cortes ilustrados nas figuras 5, 9, 13 e 15 respectivamente. 1. F. australis. 2. F. glabrescens. 3. F. pubescens. 4. F. thyrsoidea . Barras $=500 \mu \mathrm{m}$.

Figures 1-4. Diagrams of petiole outline and midrib in transection obtained from sections illustrated in figures 5, 9, 13 and 15, respectively. 1. F. australis. 2. F. glabrescens. 3. F. pubescens. 4. F. thyrsoidea . Bars $=500 \mu \mathrm{m}$. 
distinção das espécies. Forsteronia australis (figuras 1,5 ) e $F$. thyrsoidea (figuras 4,15 ) possuem o pecíolo achatado dorsiventralmente. Forsteronia glabrescens e F. pubescens têm pecíolos cilíndricos (figuras 2, 3, 9, 13). A epiderme apresenta células pequenas com paredes arqueadas (figuras $6,10,14$ ), com aspecto papiloso apenas em $F$. thyrsoidea (figuras 16, 17). O feixe vascular é bicolateral em todas as espécies e tem formato de arco tênue com as extremidades curvas em $F$. australis (figuras 5, 7) e F. glabrescens (figuras 9, 11); arco tênue em $F$. pubescens (figura 13) e arco pronunciado em formato de "V" em $F$. thyrsoidea (figura 15). Cordões de floema são observados acompanhando o feixe mediano em $F$. australis (figuras $5,7,8$ ) e $F$. thyrsoidea (figura 15 ).

Forsteronia australis difere de $F$. glabrescens quanto à distribuição dos idioblastos secretores. Em F. australis, os idioblastos são raros e possuem um conteúdo fracamente corado (figura 6), sendo encontrados no córtex, acima da nervura mediana (figura 5), e junto ao floema (figuras 7, 8). Em F. glabrescens, os idioblastos constituem uma hipoderme contínua em toda a circunferência do pecíolo; também estão presentes no parênquima cortical (figura 9) e apresentam um conteúdo acidófilo de aspecto denso fortemente corado pela safranina (figuras 10,12).

Forsteronia thyrsoidea também difere de F. pubescens quanto à posição dos idioblastos secretores, que se encontram dispersos na porção inferior do córtex e seu conteúdo apresenta coloração verde (figura 15). Idioblastos nesta posição nunca foram observados em F. pubescens (figura 13); nessa espécie, eles ocorrem associados ao floema do feixe mediano e também possuem um conteúdo acidófilo de aspecto denso, corado em vermelho pela safranina.

Laticíferos foram observados no córtex e ao redor dos feixes vasculares (indicados por setas) em todas as espécies. Suas células apresentam parede espessa em $F$. australis e $F$. glabrescens (figuras 8,12 ) e calibre maior que as demais em $F$. pubescens e $F$. thyrsoidea (figuras 13,15).

Lâmina foliar - Nas quatro espécies estudadas, a epiderme é unisseriada em ambas as faces (figuras 18, 23-26, 30, 31, 37, 38). Forsteronia australis e F. glabrescens possuem células epidérmicas com paredes anticlinais sinuosas (figuras 22 e 27 , respectivamente); em $F$. pubescens (figura 34) e $F$. thyrsoidea as paredes são retas, o que confere um aspecto poligonal a essas células.

Estômatos estão restritos à epiderme da face inferior, são predominantemente do tipo paracítico (figura 22) e encontram-se no mesmo nível das demais células epidérmicas (figuras 23, 26, 31, 38). Tricomas multicelulares unisseriados não secretores são encontrados em três espécies; em $F$. glabrescens, eles estão restritos às criptas das domácias (figura 25). Em F. pubescens (figura 36) e F. thyrsoidea, esses tricomas predominam ao longo das nervuras mediana e laterais, principalmente na face inferior. Nesta última espécie, um adensamento de tricomas tectores é observado nas axilas da nervura mediana com as laterais. Apenas a epiderme de F. australis é glabra.

Em corte transversal (figuras 18, 24, 30, 37), as células epidérmicas da nervura mediana são menos volumosas que as demais, tanto na face superior quanto na inferior. Ao longo da nervura, duas a três camadas de colênquima ocorrem junto à epiderme em ambas as faces da lâmina foliar.

O feixe vascular é bicolateral e apresenta formato de arco (figuras 18, 24, 30) à exceção de $F$. thyrsoidea, que tem arco pronunciado em forma de "V" e cinco cordões de floema voltados em direção à face adaxial (figura 37); apenas F. pubescens possui costela na nervura mediana (figura 30). O metaxilema é constituído por elementos de condução de grande calibre entremeados por células parenquimáticas pouco volumosas (figuras 18, 24, 30, 33, 37, 40). Células esclerenquimáticas são encontradas acima do floema próximo à face superior em F. australis (figura 18) e F. glabrescens (figura 24). O floema apresenta idioblastos secretores de compostos fenólicos com conteúdo de aspecto denso em $F$. australis (figura 18), F. pubescens (figura 13) e $F$. glabrescens (figuras 24, 25).

Laticíferos são encontrados ao redor do feixe vascular mediano (figuras 18, 24, 30, 33, 37, 40, 41). Essas estruturas (setas) possuem parede espessada em F. pubescens (figura 33) e calibre maior que as demais células em $F$. thyrsoidea (figuras 37, 40, 41).

As espécies apresentam mesofilo dorsiventral (figuras $23,26,38$ ) exceto $F$. pubescens (figura 31 ), cujo mesofilo é homogêneo, sem clara distinção entre parênquima paliçádico e lacunoso. O número de camadas do clorênquima é próximo de cinco em $F$. australis (figura 23 ); de três em $F$. glabrescens (figura 26) e $F$. pubescens (figura 31) e de duas em $F$. thyrsoidea (figura 38). Laticíferos são encontrados apenas em $F$. australis (figura 23).

Os feixes vasculares do mesofilo são bicolaterais em $F$. glabrescens (figura 26) e colaterais em $F$. australis (figura 23), F. pubescens (figura 31) e em F. thyrsoidea (figura 38). Em F. pubescens, a bainha parenquimática do feixe apresenta cloroplastos e as suas extensões 
atingem a epiderme em ambas as faces (figura 31). Fibras não são registradas nos feixes vasculares de F. thyrsoidea e a bainha do feixe com suas extensões são bem definidas (figura 38). Apenas $F$. pubescens apresenta costela nas nervuras laterais de primeira ordem (figura 31).

Dois tipos de idioblastos foram encontrados: os secretores, com conteúdo granuloso (figura 23) ou denso (figura 26); e os cristalíferos, sob a forma de drusas (figura 26), cristais romboidais (figura 29) ou prismáticos (figura 35).

Os idioblastos secretores estão presentes em F. australis (figuras 20, 23), F. glabrescens (figuras 24-26) e $F$. thyrsoidea (figuras 37, 41). Nas duas primeiras, eles estão distribuídos no parênquima paliçádico, onde apresentam formato retangular (figuras 23, 26) e na bainha dos feixes vasculares e suas extensões, onde são arredondados; na terceira, estão presentes no córtex, ao redor do feixe vascular mediano (figuras 37, 41). Os idioblastos de F. glabrescens são mais longos que as demais células do parênquima paliçádico (figura 26) e podem apresentar conteúdo denso (figura 26) ou granuloso (figura 25). Em $F$. australis, há somente idioblastos com conteúdo granuloso (figuras 20,23), três a quatro vezes mais longos que as células do parênquima paliçádico (figura 23).

Idioblastos cristalíferos são observados dispersos no mesofilo em todas as espécies estudadas à exceção de F. thyrsoidea. $\mathrm{O}$ formato dos cristais e sua frequiência variam de espécie para espécie. Forsteronia glabrescens apresenta drusas (figuras 26, 29) e cristais romboidais em grande quantidade (figura 29); em F. australis, ambos os tipos de cristais são raros. Forsteronia pubescens apresenta cristais prismáticos (figura 35) e drusas.

Forsteronia pubescens e $F$. thyrsoidea diferem quanto ao tipo de idioblastos que apresentam. Forsteronia pubescens possui idioblastos cristalíferos com cristais prismáticos dispersos pelo parênquima ao redor da nervura mediana (figura 30); esse tipo de idioblasto não foi registrado em $F$. thyrsoidea. Já nesta última, idioblastos secretores com conteúdo acidófilo (denso ou granuloso) são encontrados no parênquima fundamental ao redor do feixe vascular (figura 37); esses idioblastos não ocorrem nesta posição em $F$. pubescens (figura 30).

Domácias foram registradas em $F$. australis (figuras 19, 20) e $F$. glabrescens (figura 25), estando presentes nas axilas da nervura mediana com as laterais, na face inferior da lâmina foliar. Em $F$. australis, as domácias estão restritas à região mediana da lâmina, as criptas são rasas e revestidas por duas camadas de células com conteúdo granuloso; tricomas não são observados (figuras 19, 20). Em F. glabrescens, elas são encontradas ao longo da nervura mediana, em quase toda a extensão da lâmina foliar, estando ausentes apenas no ápice e na base da lâmina. São criptas profundas revestidas por duas camadas de células obliteradas; tricomas tectores multicelulares unisseriados, eretos ou recurvados, estão presentes apenas próximo à região de abertura da cripta (figura 25). Em ambas as espécies, observa-se que a cripta é formada com redução apenas do parênquima lacunoso (figuras 19, 20, 25).

Coléteres em fase secretora são encontrados nos ápices caulinares vegetativos das quatro espécies (figuras 21, 28, 32, 39). Todos eles têm origem no primórdio foliar, ocupando posição marginal ou axilar e não apresentam tecido vascular ou qualquer tipo de modificação estrutural.

Os coléteres marginais são caducos em órgãos adultos, restando apenas cicatrizes em posição interpeciolar. Os coléteres axilares são persistentes e ficam reduzidos a pequenas estruturas senescentes posicionadas na base da lâmina foliar próximas ao pecíolo, sobre a nervura mediana. O número de coléteres marginais e axilares é variável nas quatro espécies; 4-8 marginais e 2-8 axilares são encontrados em média por nó vegetativo, considerando os dois primórdios foliares com filotaxia oposta. O número de coléteres varia entre as espécies, entre indivíduos da mesma espécie e em nós diferentes de um mesmo indivíduo.

Três tipos de coléteres foram registrados: padrão, séssil e ramificado. O tipo padrão é formado por um eixo alongado recoberto por epiderme em paliçada e um pedúnculo curto (figura 21). O tipo séssil não apresenta pedúnculo e possui a paliçada secretora extremamente espessa (figura 28). O tipo ramificado é semelhante ao tipo padrão e ramifica-se ao longo do seu comprimento (figura 32). A ramificação só é registrada através da análise de cortes transversais seriados.

O tipo padrão foi encontrado nos coléteres marginais de todas as espécies; apenas $F$. pubescens possui dois tipos: padrão e séssil. Em relação aos coléteres axilares, F. australis e F. glabrescens apresentam os tipos padrão e séssil respectivamente. F. pubescens possui os três tipos; o ramificado não foi observado em $F$. thyrsoidea (tabela 2).

\section{Discussão}

Todas as espécies de Forsteronia estudadas apresentam epiderme unisseriada em ambas as faces da lâmina foliar e estômatos predominantemente paracíticos 

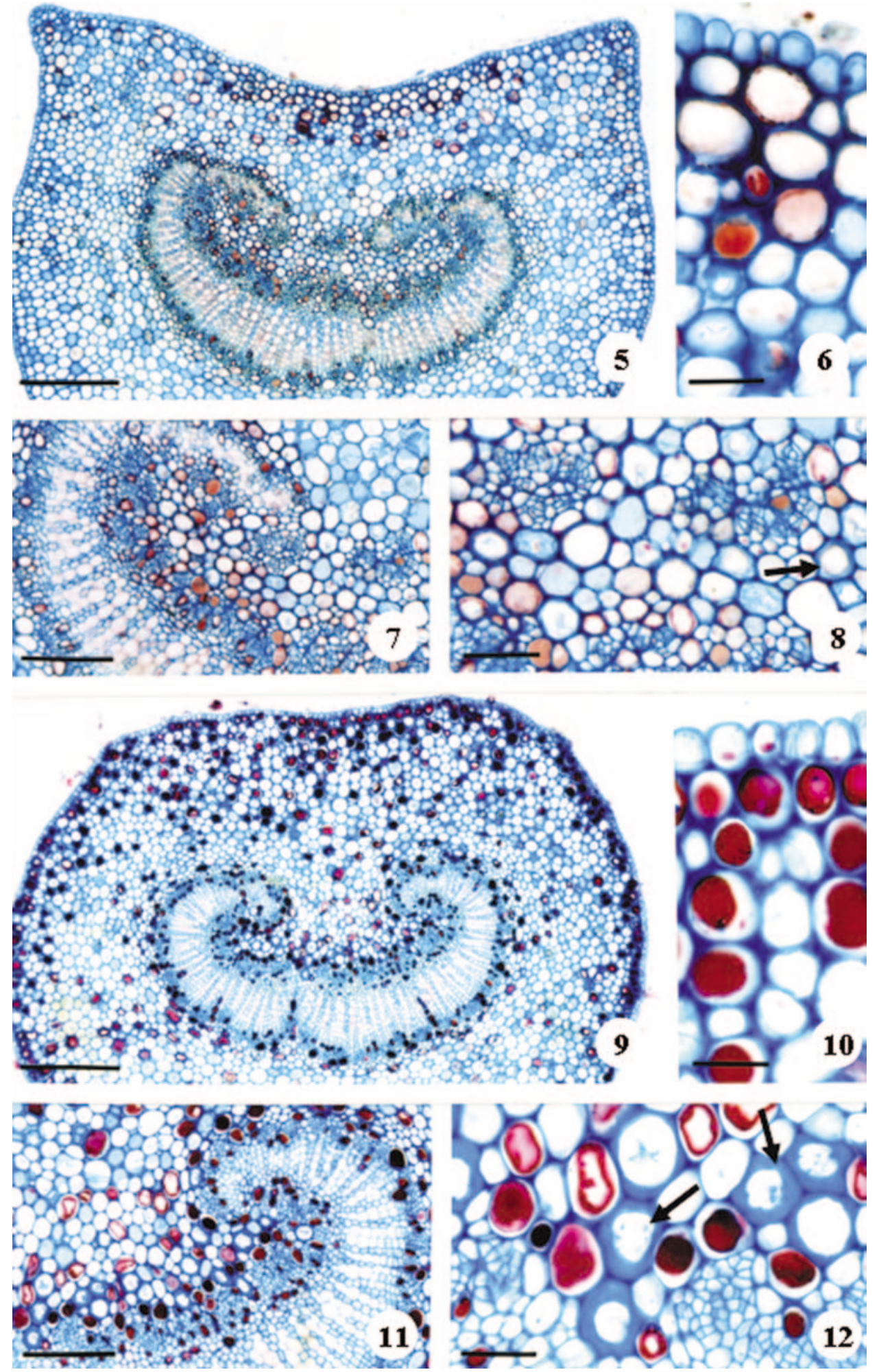

Figuras 5-12. Pecíolo de folhas adultas de F. australis (5-8) e F. glabrescens (9-12) em secções transversais. 5, 9. Vista geral. 6,10 . Detalhe da região cortical da face adaxial. 7, 11. Detalhe do feixe vascular. 8. Detalhes dos cordões floemáticos e de laticífero (seta). 12. Detalhe do floema; idioblastos e laticíferos (setas). Barras $=200 \mu \mathrm{m}(5,9), 100 \mu \mathrm{m}(7,11)$, $25 \mu \mathrm{m}(6,8,10,12)$.

Figures 5-12. Petiole of $F$. australis (5-8) and F. glabrescens (9-12) mature leaves; transections. 5, 9. General view. 6, 10. Region above midrib. 7, 11. Vascular bundle. 8. Phloem strands and laticifer (arrow). 12. Phloem; idioblasts and laticifers (arrows). Bars $=200 \mu \mathrm{m}(5,9), 100 \mu \mathrm{m}(7,11), 25 \mu \mathrm{m}(6,8,10,12)$. 

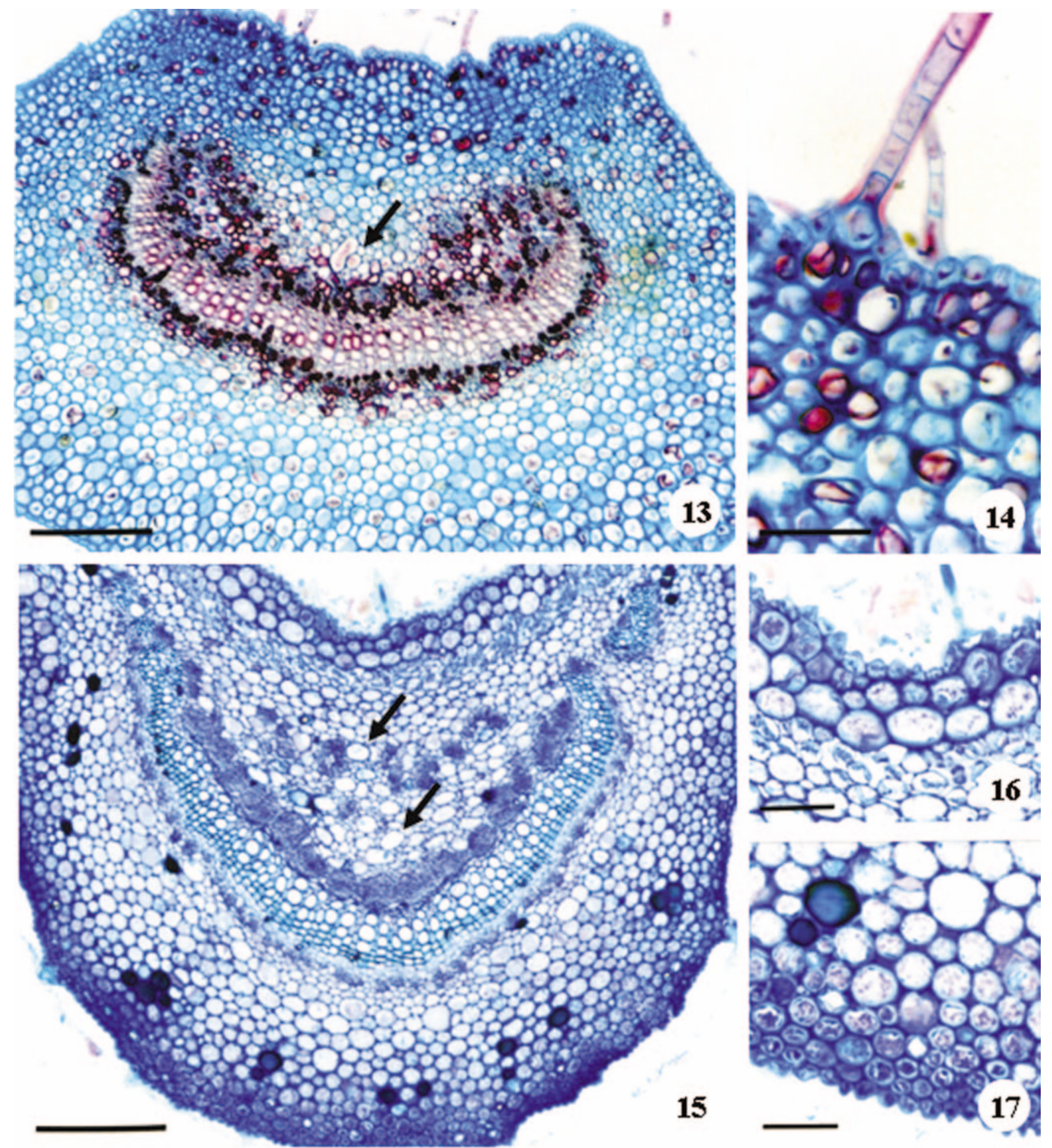

Figuras 13-17. Pecíolo de folhas adultas de F. pubescens (13-14) e F. thyrsoidea (15-17) em secções transversais. 13, 15 . Vista geral; laticíferos (setas). 14. Detalhe da região cortical da face adaxial. 16-17. Detalhes da epiderme das faces superior (16) e inferior (17); células epidérmicas papilosas. Barras $=200 \mu \mathrm{m}(13,15), 50 \mu \mathrm{m}(14,16,17)$.

Figures 13-17. Petiole of $F$. pubescens (13-14) and $F$. thyrsoidea (15-17) mature leaves; transections. 13, 15. General view; laticifers (arrows). 14. Region above midrib. 16-17. Upper (16) and lower (17) papillose epidermis. Bars $=200 \mu \mathrm{m}$ $(13,15), 50 \mu \mathrm{m}(14,16,17)$. 

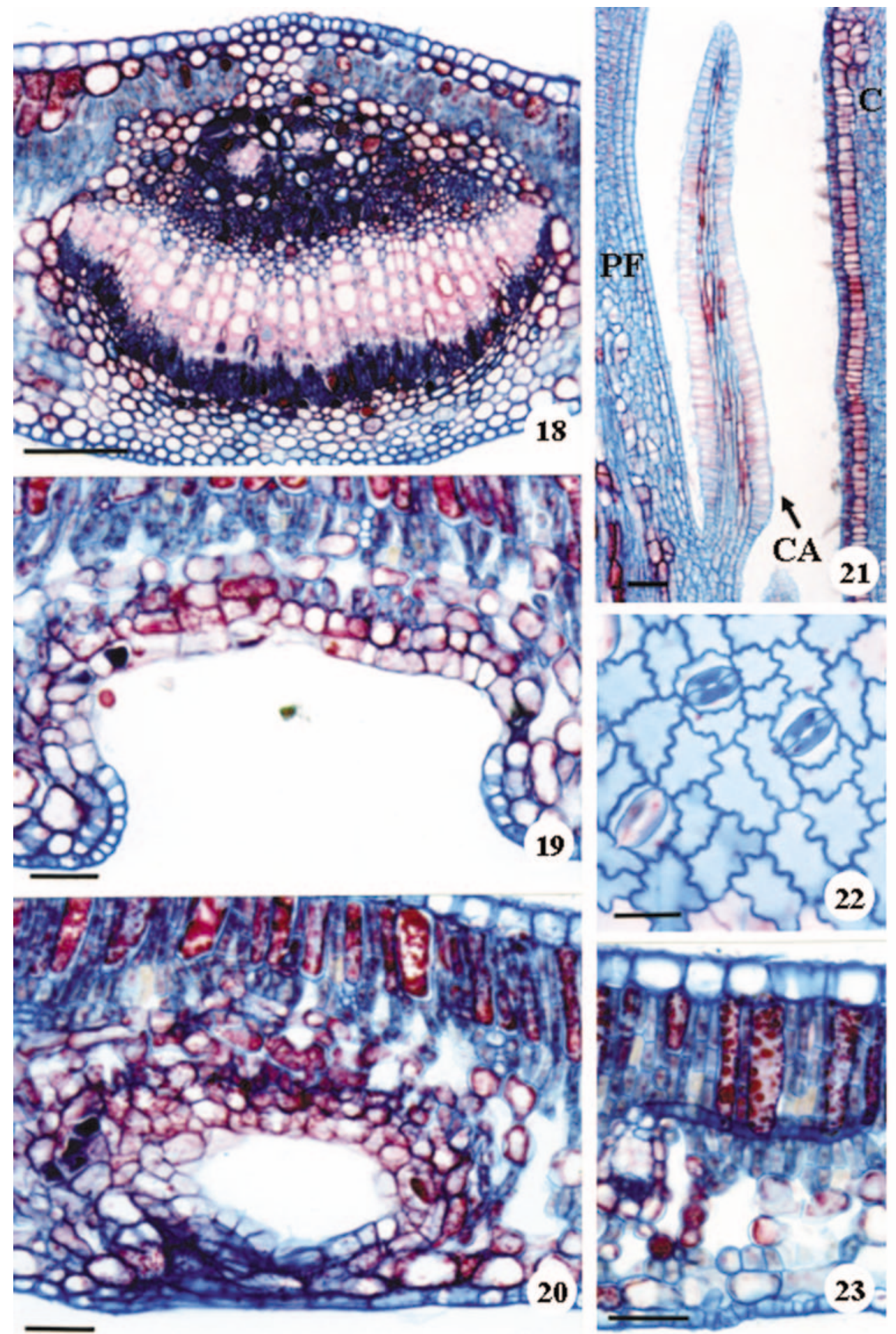

Figuras 18-23. Folha adulta $(18-20,22-23)$ e primórdio foliar (21) de $F$. australis em secções transversais $(18-20,23)$ e longitudinais (21-22). 18. Nervura mediana. 19. Domácia em secção transversal mediana. 20. Domácia em secção tangencial. 21. Coléter axilar padrão. 22. Epiderme da face abaxial em vista frontal; estômatos paracíticos e células com paredes sinuosas. 23. Mesofilo dorsiventral; laticífero e feixe vascular lateral. $\mathrm{C}=$ caule; $\mathrm{CA}=$ coléter axilar; $\mathrm{PF}=$ primórdio foliar. Barras $=100 \mu \mathrm{m}(18), 50 \mu \mathrm{m}(19-21,23), 25 \mu \mathrm{m}$ (22).

Figures 18-23. Mature (18-20, 22-23) and young leaf (21) of $F$. australis; transections $(18-20,23)$ and longisections (21-22). 18. Midrib. 19. Median transection of domatia. 20. Tangential transection of domatia. 21. Standard axilar colleter. 22. Lower epidermis in surface view; paracytic stomata and wavy walls. 23. Dorsiventral mesophyll; laticifer and lateral vascular bundle. $\mathrm{C}=$ stem; $\mathrm{CA}=$ axilar colleter; $\mathrm{PF}=$ young leaf. $\mathrm{Bars}=100 \mu \mathrm{m}(18), 50 \mu \mathrm{m}(19-21,23), 25 \mu \mathrm{m}(22)$. 

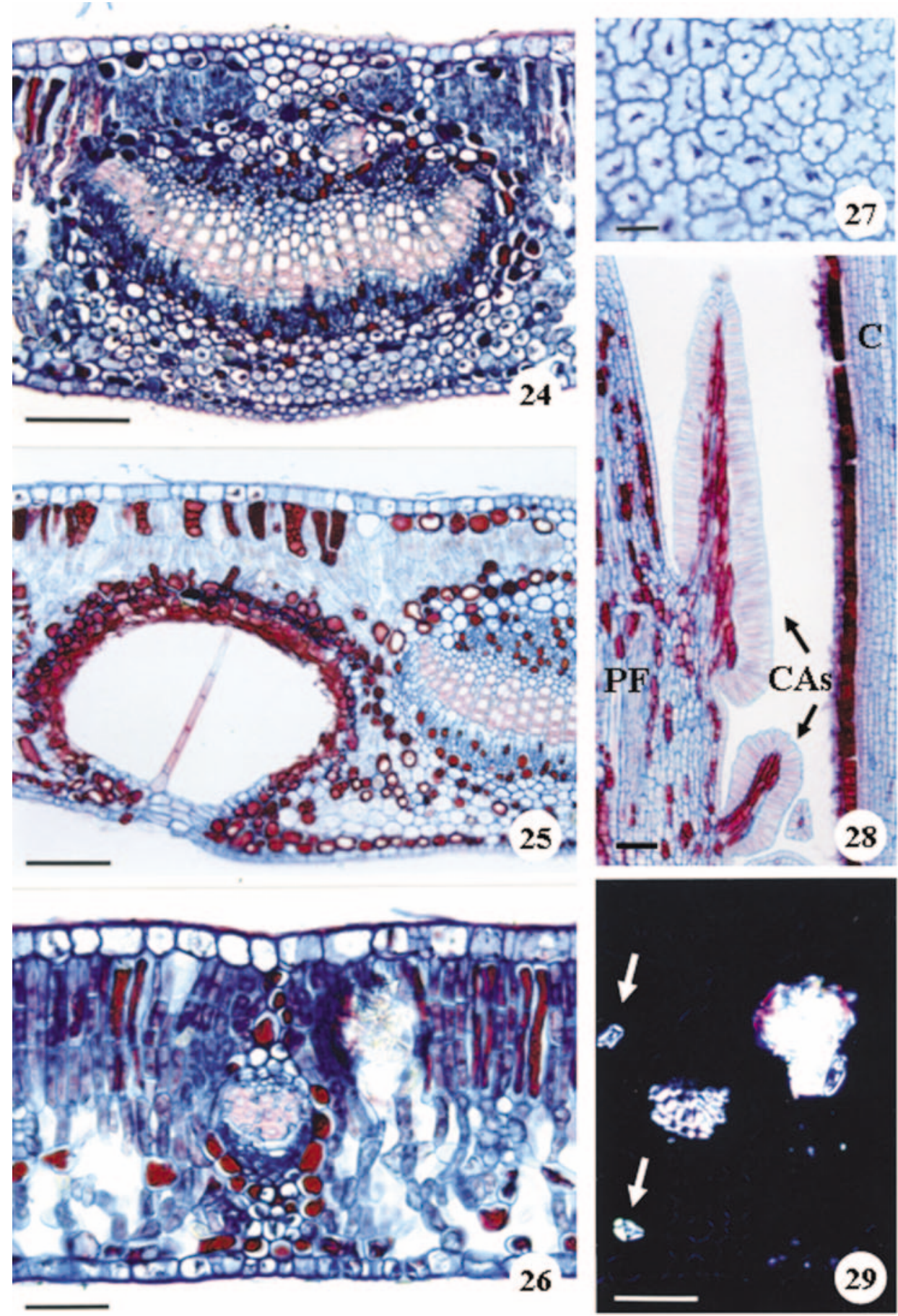

Figuras 24-29. Folha adulta $(24-27,29)$ e primórdio foliar (28) de F. glabrescens em secções transversais (24-26, 29) e longitudinais (27-28). 24. Nervura mediana. 25. Domácia; tricoma tector multicelular unisseriado. 26. Mesofilo dorsiventral; idioblastos com conteúdo denso no parênquima paliçádico, na bainha do feixe vascular e extensões. 27 . Epiderme da face adaxial em vista frontal com células de paredes sinuosas. 28. Coléter axilar séssil. 29. Mesofilo em luz polarizada; drusa e cristais romboidais (setas). $\mathrm{C}=$ caule; $\mathrm{CAs}=$ coléteres axilares; $\mathrm{PF}=$ primórdio foliar. Barras $=100 \mu \mathrm{m}(24,25), 50 \mu \mathrm{m}(26,28,29)$, $25 \mu \mathrm{m}(27)$.

Figures 24-29. Mature (24-27, 29) and young leaf (28) of F. glabrescens; transections (24-26, 29) and longisections (27-28). 24. Midrib. 25. Domatia; multicellular uniseriate trichome. 26. Dorsiventral mesophyll; idioblasts with dense contents in palisade parenchyma, bundle sheaths and bundle-sheath extensions. 27. Upper epidermis in surface view with wavy walls. 28. Sessile axilar colleter. 29. Mesophyll observed under polarized light; druse and rhomboid (arrows) crystal. $\mathrm{C}=$ stem; $\mathrm{CA}=$ axilar colleter; $\mathrm{PF}=$ young leaf. $\mathrm{Bars}=100 \mu \mathrm{m}(24,25), 50 \mu \mathrm{m}(26,28,29), 25 \mu \mathrm{m}(27)$. 

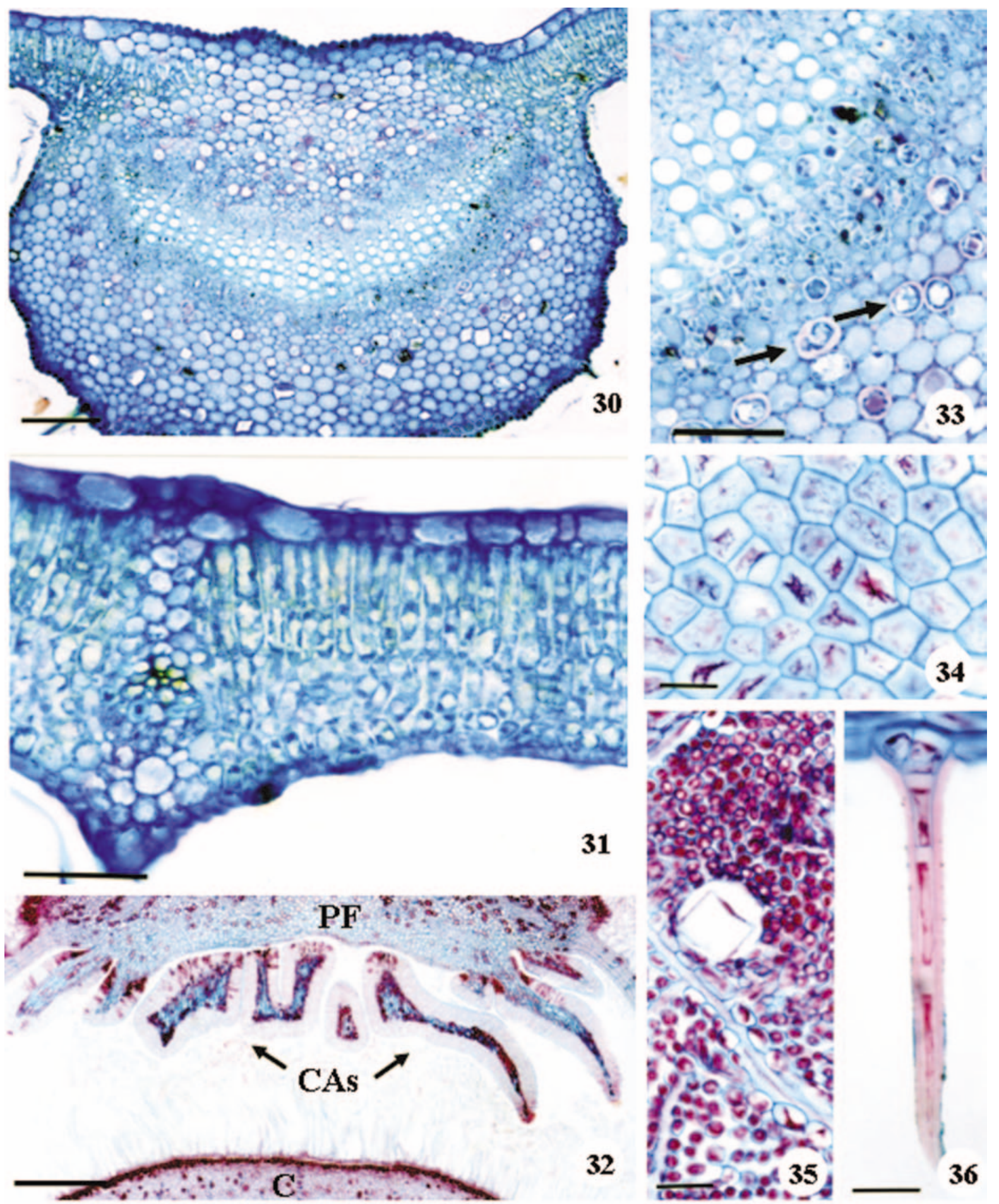

32

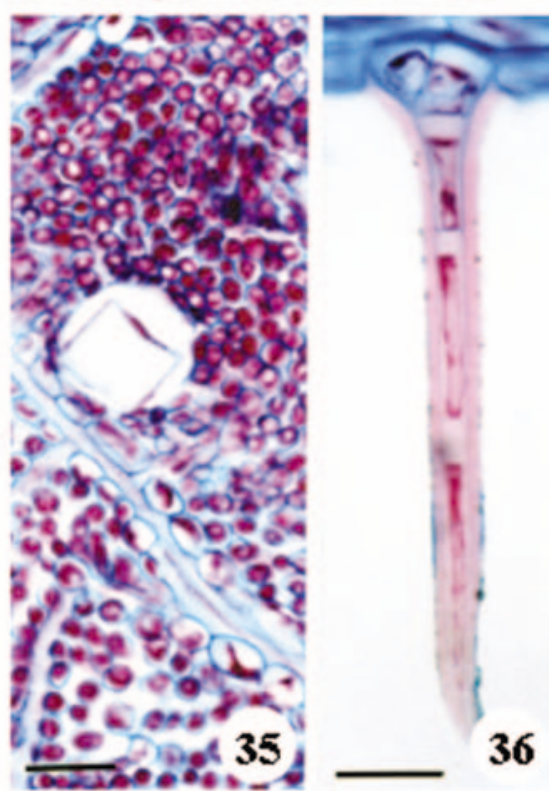

Figuras 30-36. Folha adulta (30-31, 33-36) e primórdio foliar (32) de F. pubescens em secções transversais $(30-33$, 36) e longitudinais (34-35). 30. Nervura mediana. 31. Mesofilo homogêneo; feixe vascular lateral. 32. Coléteres axilares ramificados. 33. Detalhe do feixe vascular mediano; laticíferos (setas). 34. Epiderme da face adaxial em vista frontal; células com paredes retas. 35. Cristal prismático no mesofilo. 36. Tricoma tector multicelular unisseriado. $\mathrm{C}=$ caule; CAs $=$ coléteres axilares; $\mathrm{PF}=$ primórdio foliar. Barras $=200 \mu \mathrm{m}(32), 100 \mu \mathrm{m}(30), 50 \mu \mathrm{m}(31,33), 25 \mu \mathrm{m}(34-36)$.

Figures 30-36. Mature (30-31, 33-36) and young leaf (32) of $F$. pubescens; transections $(30-33,36)$ and longisections (34-35). 30. Midrib. 31. Regular mesophyll; lateral vascular bundle. 32. Branched axilar colleters. 33. Detailed view of midrib; laticifers (arrows). 34. Upper epidermis in surface view; straight walls. 35. Prismatic crystal. 36. Multicellular uniseriate trichome. $\mathrm{C}=$ stem; $\mathrm{CAs}=$ axilar colleter; $\mathrm{PF}=$ young leaf. $\mathrm{Bars}=200 \mu \mathrm{m}(32), 100 \mu \mathrm{m}(30), 50 \mu \mathrm{m}(31,33), 25 \mu \mathrm{m}(34-36)$. 

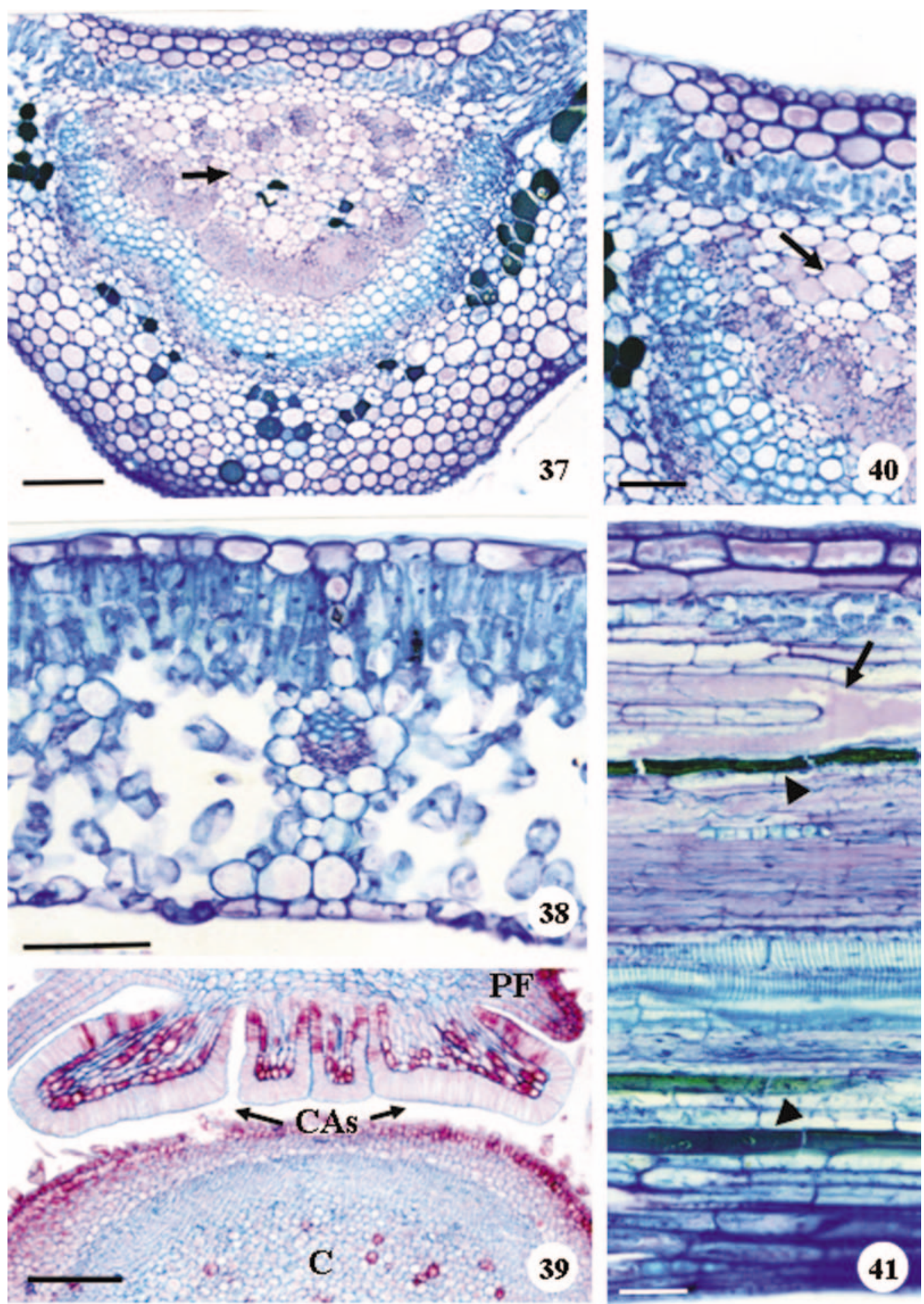

Figuras 37-41. Folha adulta (37-38, 40-41) e primórdio foliar (39) de F. thyrsoidea em secções transversais (37-40) e longitudinal (41). 37. Nervura mediana; laticíferos (seta). 38. Mesofilo dorsiventral; feixe vascular lateral e estômatos. 39. Coléteres axilares não ramificados. 40-41. Detalhe da nervura mediana. 40. Colênquima e laticíferos (seta). 41. Idioblastos secretores (cabeças de seta) e laticífero (seta). $\mathrm{C}=$ caule; $\mathrm{CAs}=$ coléteres axilares; $\mathrm{PF}=$ primórdio foliar. Barras $=100 \mu \mathrm{m}(37,39), 50 \mu \mathrm{m}(38,40,41)$.

Figures 37-41. Mature (37-38, 40-41) and young leaf (39) of F. thyrsoidea; transections (37-40) and longisections (41). 37. Midrib; laticifers (arrow). 38. Dorsiventral mesophyll; lateral vascular bundle and stomata. 39. Not branched axilar colleters. 40-41. Detailed view of midrib. 40. Colenchyma and laticifers (arrow). 41. Secretory idioblasts (arrow heads) and laticifer (arrow). $C=$ stem; $C A s=$ axilar colleter; $P F=$ young leaf. Bars $=100 \mu \mathrm{m}(37,39), 50 \mu \mathrm{m}(38,40,41)$. 
Tabela 2. Tipo de coléteres nas espécies de Forsteronia. $\mathrm{P}=$ padrão; $\mathrm{S}=$ séssil; $\mathrm{R}=$ ramificado.

Table 2. Colleters types of Forsteronia species. $\mathrm{P}=$ standard; $\mathrm{S}=$ sessile; $\mathrm{R}=$ branched.

\begin{tabular}{lcc}
\hline & Marginais & Axilares \\
\hline Forsteronia australis & $\mathrm{P}$ & $\mathrm{P}$ \\
F. glabrescens & $\mathrm{P}$ & $\mathrm{S}$ \\
F. pubescens & $\mathrm{P}, \mathrm{S}$ & $\mathrm{P}, \mathrm{S}, \mathrm{R}$ \\
F. thyrsoidea & $\mathrm{P}$ & $\mathrm{P}, \mathrm{S}$ \\
\hline
\end{tabular}

restritos à face inferior, assim como feixe vascular em forma de arco na nervura mediana. Esses caracteres foram anteriormente registrados para as folhas de Allamanda neriifolia Hook. (hoje A. schottii Pohl), Thevetia peruviana (Pers.) K.Schum e Vinca minor L., consideradas xeromórficas por Fjell (1983).

Todas as espécies analisadas neste trabalho à exceção de $F$. pubescens apresentam mesofilo dorsiventral, da mesma forma que A. neriifolia, T. peruviana e V. minor (Fjell 1983). Segundo Metcalfe \& Chalk (1950), este é o tipo de mesofilo mais comum em Apocynaceae, podendo ocorrer raramente mesofilo isobilateral. Idioblastos secretores de compostos fenólicos com conteúdo granuloso ou denso estão presentes no parênquima paliçádico apenas em $F$. australis e F. glabrescens respectivamente. Esse tipo de idioblasto não foi registrado nas espécies estudadas por Fjell (1983); Metcalfe \& Chalk (1950) mencionaram a ocorrência de células secretoras abaixo do parênquima paliçádico em Cleghornia, Echites, Kopsia e Tabernaemontana. Idioblastos cristalíferos (drusas e cristais prismáticos ou romboidais) são encontrados nas espécies de Forsteronia estudadas, à exceção de $F$. thyrsoidea. Cristais foram anteriormente registrados em A. neriifolia e T. peruviana (Fjell 1983), sendo as drusas o tipo mais comum, e em Acokanthera, Alstonia, Apocynum, Cerbera, Gonioma, Hunteria e Oncinotis (Metcalfe \& Chalk 1950).

O tipo de idioblasto cristalífero varia entre as espécies estudadas; este não é considerado um caráter diagnóstico importante, pois pode variar com o meio ambiente (Metcalfe 1983). Os cristais podem estar presentes em maior ou menor quantidade de acordo com a composição do solo onde a planta se encontra. $\mathrm{O}$ estudo de um maior número de indivíduos, inclusive de outras localidades, seria necessário para avaliar melhor a questão da variação da frequiência dos cristais.

Tricomas de vários tipos podem ser encontrados em Apocynaceae (Metcalfe \& Chalk 1950). Em Forsteronia, apenas tricomas multicelulares unisseriados não secretores (tipo 1) são observados em três das espécies estudadas. Os coléteres presentes nos nós vegetativos e na base da lâmina foliar das quatro espécies de Forsteronia estudadas não são considerados tricomas e sim emergências, uma vez que sua origem não é exclusivamente protodérmica.

O termo domácia é usualmente aplicado a tufos de tricomas, depressões, bolsos ou sacos presentes nas axilas das nervuras de maior calibre, quando ocorrem exclusivamente na face inferior das folhas (Wilkinson 1979). Segundo Brouwer \& Clifford (1990), as domácias foram definidas pela primeira vez como formações ou transformações em plantas com função de hospedar simbiontes durante um período essencial do seu desenvolvimento, configurando mutualismo. Vários autores consideram que há uma relação restrita entre as domácias e organismos animais, principalmente ácaros e formigas (Wilkinson 1979). Domácias são encontradas predominantemente em plantas lenhosas de regiões tropicais úmidas ou subtropicais; apesar de estarem presentes em plantas de regiões frias, nunca foram registradas em espécies que ocorrem em solos permanentemente secos. Os tipos de domácias foliares já descritos são: tufos de tricomas, bolsos, sacos (bolsos estendidos), criptas e margem revoluta na base da lâmina (Wilkinson 1979).

Dentre as espécies estudadas, domácias são registradas em $F$. australis e $F$. glabrescens, constituindo-se um importante caráter macromorfológico devido à presença de tricomas na cripta. As características anatômicas das domácias encontradas em Forsteronia assemelham-se às descritas por Wilkinson (1979), principalmente quanto à compactação das células, redução do número de camadas do parênquima lacunoso na região da cripta e ausência de estômatos na epiderme interna. Diferentemente do descrito por essa autora, nenhum tecido de sustentação foi encontrado ao redor da domácia. A descrição da anatomia das domácias foliares é inédita para espécies de Apocynaceae. A distribuição das domácias não se mostrou um caráter consistente para a identificação de espécies a partir dos indivíduos coletados em estádio vegetativo, uma vez que se observou uma grande variação entre diferentes indivíduos da mesma espécie e entre diferentes folhas de um mesmo indivíduo. No entanto, a ocorrência de tricomas nas domácias é sempre constante e independe do número de domácias por folha.

Coléter do tipo padrão, caracterizado pela presença de um eixo alongado recoberto por epiderme em paliçada e um pedúnculo curto (Lersten 1974), foi encontrado em todas as espécies estudadas de Forsteronia. Este 
termo, proposto para coléteres de Rubiaceae, tem sido amplamente utilizado na descrição dos coléteres de várias famílias, inclusive Apocynaceae (Thomas 1991, Appezzato-da-Glória \& Estelita 2000, Rio et al. 2002). Além de coléteres do tipo padrão, coléteres sésseis foram registrados em $F$. glabrescens, $F$. pubescens, $F$. thyrsoidea e coléteres ramificados em $F$. pubescens (tabela 2). Os tipos séssil e ramificado são descritos pela primeira vez para órgãos vegetativos de espécies de Apocynaceae.

Considerando-se as espécies estudadas, os coléteres marginais são caducos em órgãos completamente desenvolvidos, restando apenas cicatrizes em posição interpeciolar, restringindo sua utilização para fins taxonômicos. O tipo dos coléteres axilares é um caráter constante e importante na distinção entre $F$. australis e $F$. glabrescens, e entre $F$. pubescens e $F$. thyrsoidea, devendo ser observado nos ápices caulinares vegetativos (tabela 3). Os coléteres observados nestas espécies de Forsteronia são equivalentes às glândulas nodais e foliares registradas por Hansen (1985).

O número de coléteres encontrados por nó vegetativo é variável em diferentes indivíduos de uma mesma espécie e em folhas de um mesmo indivíduo, e por isto não constitui um caráter útil para fins taxonômicos. Variações no número de coléteres em folhas de uma mesma espécie são comuns e já foram relatadas para outras espécies de Apocynaceae (Ramayya \& Bahadur 1968, Thomas \& Dave 1989, Thomas 1991).

Forsteronia australis distingue-se de F. glabrescens pelo contorno do pecíolo em secção transversal, ocorrência dos idioblastos secretores no pecíolo e nervura mediana e ocorrência de cordões de floema acima do feixe vascular no pecíolo. Essas características, somadas à ocorrência de tricomas nas domácias, ocorrência de laticíferos no mesofilo e tipo dos coléteres axilares, constituem um conjunto de caracteres taxonomicamente consistentes para diagnóstico destas espécies a partir de indivíduos coletados apenas em estádio vegetativo.

Forsteronia pubescens diferencia-se de $F$. thyrsoidea pelo contorno do pecíolo e formato do feixe vascular em secção transversal, tipo de mesofilo, ocorrência de idioblastos cristalíferos, ocorrência de cordões de floema acima do feixe vascular e ocorrência de idioblastos secretores ao redor do feixe vascular mediano da lâmina foliar.

Os principais caracteres diagnósticos das folhas adultas das espécies estudadas de Forsteronia de cerrado referem-se às domácias; ocorrência, tipo e posição das estruturas secretoras e formato do feixe vascular mediano em secção transversal. Alguns caracteres destacam-se

Tabela 3. Caracteres diagnósticos levantados para Forsteronia australis, F. glabrescens, F. pubescens e F. thyrsoidea. + = presença; - = ausência; $\mathrm{P}=$ padrão; $\mathrm{S}=$ séssil; $\mathrm{R}=$ ramificado.

Table 3. Diagnostic character survey of Forsteronia australis, F. glabrescens, F. pubescens e F. thyrsoidea. $+=$ presence; - = absence $; \mathrm{P}=$ standard $; \mathrm{S}=$ sessile $; \mathrm{R}=$ branched.

\begin{tabular}{|c|c|c|c|c|c|}
\hline & Caracteres diagnósticos & F. australis & F. glabrescens & F. pubescens & F. thyrsoidea \\
\hline \multirow[t]{5}{*}{ Pecíolo } & $\begin{array}{l}\text { Contorno em secção transversal } \\
\text { Cordões de floema acima do feixe }\end{array}$ & achatado & cilíndrico & cilíndrico & achatado \\
\hline & vascular & + & - & - & + \\
\hline & Hipoderme secretora & - & + & - & - \\
\hline & Formato do feixe vascular & arco tênue & arco tênue & arco tênue & arco pronunciado $(\mathrm{V})$ \\
\hline & Posição dos idioblastos secretores & floema & floema e córtex & floema & córtex \\
\hline \multirow[t]{11}{*}{ Lâmina foliar } & Domácias & + & + & - & - \\
\hline & Indumento nas domácias & - & + & & \\
\hline & Idioblastos secretores na nervura & & & & \\
\hline & mediana & + & + & - & - \\
\hline & $\begin{array}{l}\text { Aspecto do conteúdo dos } \\
\text { idioblastos }\end{array}$ & granuloso & denso & & \\
\hline & Tipo de coléter axilar & $\mathrm{P}$ & $\mathrm{S}$ & $\mathrm{P}, \mathrm{S}, \mathrm{R}$ & $\mathrm{P}, \mathrm{S}$ \\
\hline & Tipo de mesofilo & dorsiventral & dorsiventral & homogêneo & dorsiventral \\
\hline & Idioblastos cristalíferos & + & + & + & - \\
\hline & Idioblastos secretores no córtex & & & & \\
\hline & da nervura mediana & + & + & - & + \\
\hline & Coléter axilar ramificado & - & - & + & - \\
\hline
\end{tabular}


pela facilidade de observação na lupa ou através da obtenção de cortes a mão livre, diferenciando $F$. australis de $F$. glabrescens e $F$. pubescens de $F$. thyrsoidea (tabela 3).

Agradecimentos - As autoras agradecem à Fundação de Amparo à Pesquisa do Estado de São Paulo (Fapesp) pela bolsa de doutorado (proc. 01/05341-3) e pelo auxílio à pesquisa do projeto temático (Biota/Fapesp proc. 00/12469-3) concedidos.

\section{Referências bibliográficas}

APPEZZATO-DA-GLÓRIA, B. \& ESTELITA-TEIXEIRA, M.E.M. 1992. Anatomia do sistema aéreo vegetativo de Mandevilla pohliana (Stadelm.) A. Gentry (Apocynaceae). Hoehnea 19:39-50.

APPEZZATO-DA-GLÓRIA, B. \& ESTELITA, M.E.M. 1997. Laticifer systems in Mandevilla illustris and M. velutina Apocynaceae. Acta Societatis Botanicorum Poloniae 66:301-306.

APPEZZATO-DA-GLÓRIA, B. \& ESTELITA, M.E.M. 2000. Development, structure and distribuition of colleters in Mandevilla illustris and M. velutina (Apocynaceae). Revista Brasileira de Botânica 23:113-120.

BROUWER, Y.M. \& CLIFFORD, H.T. 1990. An annotated list of domatia-bearing species. Notes from the Jodrell Laboratory 12:1-33.

CLARK, G. 1973. Staining procedures. The Williams \& Wilkins Co., Baltimore.

ENDRESS, M.E. \& BRUYNS, P.V. 2000. A revised classification of Apocynaceae s.l. The Botanical Review 66:1-56.

FJELL, I. 1983. Anatomy of the xeromorphic leaves of Allamanda neriifolia, Thevetia peruviana and Vinca minor (Apocynaceae). Nordic Journal of Botany 3:383-392.

GERLACH, D. 1969. Botanische Mikrotechnik: Eine Einführung. Georg Thieme, Stuttgart.

GERRITS, P.A. 1991. The application of glycol methacrilate in histotechnology; some fundamental principles. Department of Anatomy and Embryology State University Groningen, Netherlands.

GREGORY, M. 1990. Additional records of occurrence of domatia. Notes from the Jodrell Laboratory 12:34-50.

HANSEN, B.F. 1985. A monografic revision of Forsteronia (Apocynaceae). PhD Thesis. University of South Florida, Tampa.

JOHANSEN, D.A. 1940. Plant microtechnique. McGraw-Hill, New York.

KOCH, I. \& KINOSHITA, L.S. 2005. Apocynaceae Forsteronia G.Mey. In Flora Fanerogâmica do Estado de São Paulo (M.G.L. Wanderley, G.J. Shepherd, T.S. Melhem \& A.M. Giulietti, coords.). Fapesp, Rima, São Paulo, v.4, p.48-53.
LERSTEN, N.R. 1974. Morphology and distribution of colleters and crystals in relation to the taxonomy and bacterial leaf nodule symbiosis of Psychotria (Rubiaceae). American Journal of Botany 61:973-981.

METCALFE, C.R. 1983. Secreted mineral substances. In Anatomy of the dicotyledons. Wood structure and conclusion of the general introduction (C.R. Metcalfe \& L. Chalk, eds.). Clarendon Press, Oxford, v.2, p.82-97.

METCALFE, C.R. \& CHALK, L. 1950. Anatomy of the dicotyledons: leaves, stem and wood in relation to taxonomy with notes on economic uses. Clarendon Press, Oxford.

METCALFE, C.R. \& CHALK, L. 1979. Anatomy of the dicotyledons. Systematic anatomy of leaf and stem, with a brief history of the subject. Clarendon Press, Oxford.

MOHAN, J.S.S. \& INAMDAR, J.A. 1982. Leaf architecture of Apocynaceae. Proceedings of Indian Academy of Science (Plant Science) 91:189-200.

MONTEIRO, W.R., GIULIETTI, A.M., MAZZONI, S.C. \& CASTRO, M.M. 1979. Hairs on reproductive organs of some Eriocaulaceae and their taxonomic significance. Boletim de Botânica, Universidade de São Paulo 7:43-59.

O'BRIEN, T.P., FEDER, N. \& MCCULLY, M.E. 1964. Polychromatic staining of plant cell walls by toluidine blue O. Protoplasma 59:368-373.

RAMAYYA, N. \& BAHADUR, B. 1968. Morphology of the "squamellae" in the light of their ontogeny. Current Science 18:520-522.

RIO, M.C.S., CASTRO, M.M. \& KINOSHITA, L.S. 2002. Distribuição e caracterização anatômica dos coléteres foliares de Prestonia coalita (Vell.) Woodson (Apocynaceae). Revista Brasileira de Botânica 25:339-349.

SMITH, F.H. \& SMITH, E.C. 1942. Anatomy of the inferior ovary of Darbya. American Journal of Botany 29:464-471.

SOLEREDER, H. 1908. Systematic anatomy of the dicotyledons. Clarendon Press, Oxford.

THOMAS, V. 1991. Structural, fuctional and phylogenetic aspects of the colleter. Annals of Botany 68:287-305.

THOMAS, V. \& DAVE, Y. 1989. Histochemistry and senescence of colleters of Allamanda cathartica L. (Apocynaceae). Annals of Botany 64:201-203.

THOMAS, V. \& DAVE, Y. 1991. Comparative and phylogenetic significance of colleters in Apocynaceae. Feddes Repertorium 102:23-28.

THOMAS, V., DAVE, Y. \& MENON, A.R.S. 1989. Anatomy and histochemistry of colleters in Roupelia grata (Apocynaceae). Nordic Journal of Botany 8:493-496.

WILKINSON, H.P. 1979. The plant surface (mainly leaf). In Anatomy of the dicotyledons. Systematic anatomy of leaf and stem, with a breaf history of the subject (C.R. Metcalfe \& L. Chalk, eds.). Clarendon Press, Oxford, v.1, p.97-165.

WILLIAMS, R.F., METCALFE, R.A. \& GUST, L.W. 1982. The genesis of form in oleander (Nerium oleander L.). Australian Journal of Botany 30:677-687. 